\title{
Michael Schuenke, Erik Schulte, Udo Schumacher, Laurence M. Ross, Edward D. Lamperti, Ethan Taub: THIEME atlas of anatomy head and neuranatomy
}

\author{
Georg Thieme Verlag, Stuttgart, New York, 2006, 420 pp, 1182 illustrations, \\ 72 tables, € 59.95 (Softcover), ISBN 13: 978-1-58890-361-7 (Hardcover), \\ ISBN 13: 978-3-13-142101-2 (Hardcover), ISBN 13: 978-1-58890-441-5 (Softcover), \\ ISBN 13: 978-3-13-142101-2 (Softcover)
}

\section{Pierre Kehr}

Received: 16 August 2009 / Accepted: 18 August 2009 / Published online: 2 September 2009

(C) Springer-Verlag 2009

This book of anatomy is a genuine work of art; drawings, integrating the most recent advances in medical imaging, are magnificent and perfectly legible. An outline of the different planes is provided for the majority of anatomical drawings using a colour code.

Lavishly detailed anatomical sections of the cerebrospinal system are accompanied by explanations often complemented by drawings, allowing to understand the clinical symptomatology related to the affected area. The anatomical sections can be worthily and easily compared with CT sections or patients' MRI.

A very detailed index is also included enabling easy access to the items.

It is recommended to students and scholars who need to relate anatomical facts to clinical practice.

No funds were received in support of this study.

Pierre Kehr Strasbourg

P. Kehr ( $\square)$

ArgoSpine, Strasbourg, France

e-mail: kehrpier@aol.com 